DE91 005720

DOE GRAn'T DE-FG05-88ER13943

\title{
Theoretical and Experimental Study of Mixed Solvent ELECTROL'TES
}

\author{
P. T. CUMmings and J. P. O'CONNELl \\ Department of Cimemical Engineering \\ THORNTON Hall, University of Virginia \\ Charlot'tesítlle, VA 22901
}

\author{
Submitted to: Dr. F. D. Stevenson \\ DEPARTMENT OF ENERGY \\ 19901 Germantown ROAD \\ GERMANTOWN, MD 20874
}

\section{SUMMARY}

In Section I of this Report, we briefly progress during the second funding period (1/1/90-12/31/90) and describe plans for the third and final funding period (1/1/91-12/31/91). Progress has been made on the four main objectives of the research program as originally envisaged. The research has also broadened somewhat into the the related area of electrolytes in compressible media. We have also strengthened our program by collaboration with researchers at Oak Ridge National Laboratory in Oali Ridge, TN and the ivational Institute of Standards and Technology in Gaithersburg, MD.

During the current period, five manuscripts have been sulmitted for publication acknowledging DOE support from this grant and five papers based on work completed this year have been subnitted or accepted for presentation at conferences during this and the coming year.

\section{DISCLAIMER}

This report was prepared as an account of work sponsored by an agency of the United States Grvernment. Neither the United States Gnvernment nor any agency thereof, nor any of their employees, makes any warranty, express or implied, or assumes any legal liability or responsibility for the accuracy, completeness, or usefulness of any information, apparatus, product, or process disclosed, or represents that its use would not infringe privately owned rights. Reference herein to any specific commercial product, process, or service by trade name, trademark, manufacturer, or otherwise does not necessarily constitute or imply its endorsement, recommendation, or favoring by the United States Government or any agency thereof. The views and opinions of authors expressed herein do not necessarily state or reflect those of the United States Government or any agency thereof. 


\section{Progress During Period 1/1/90- $12 / 31 / 90$.}

In the original proposal to study mixed solvent electrolyte solutions, four major goals were formulated:

1. Fundamental modeling of mixed solvent electrolytes using numerically solved integral equation approximation theories

2. Evaluation of intermolccular pair potential models by computer simulation of selected systens for comparison with experinent and the numerical integral equation studies

3. Development of fundamentally based correlations for the thermodynamic properties of mixed solvent electrolytc solutions using analytically solvable statistical mechanical models

4. Extension of experimental database on mixed solvent electrolytes by performing vapor-liquid equilibrium measurements on selected systems

Progress on these four goals during the first grant period, $T / 1 / 88$ $12 / 31 / 89$, was described in the previous report. Briefly stated, substantial progress was made on goals $1-3$ and some difficulties associated with the experimental work were noted.

In the last report, we described the proposed research for the current, grant period $(1 / 1 / 90-12 / 31 / 90)$ :

1. Shorten the time required to develop programs for solving the molecular OZ equation (goal 1 above) by initiating a collaboration with Professor Fred Lado at North Carolina State University.

2. Perform Gibbs ensemble simulations of water, water/methanol, water $/ \mathrm{NaCl}$ and water/methanol/ $\mathrm{NaCl}$ and compare the result ing phase equilibria with our own experinental data.

3. Compute the dielectric propertice of the SPC model for water by three different routes: Monte Carlo simulation using the Ewald sum 
(already completed by doctoral candidate Mr. H. Strauch); molecular dynamics using the Ewald sum (to be performed by M.S. recipient Mr. N. Beil); and molecular dynamics using the spherical cutoff plus reaction field method (to be performed by postdoctoral worker Dr. S. Karaborni).

4. Complete the analysis of the mean spherical approximation for the ion-containing dipolar mixture and begin to use this as an analytic basis for developing correlations of mixed solvent electrolyte systems.

5. Confirm our preliminary experimental results on the effect of tetra alkyl ammonium salts on butanol.

6. Wirite the fluctuation solution theory for weak electrolytes in terms of common quantities.

7. Make better connections to traditional approaches for multicomponent salts and solvents.

8. Determine where model failures occur.

9. Relate experimental results to the theoretical models.

10. Establish collaborative efforts with researchers at NIST Gaithersburg and ORNL Oak Ridge in the areas of mixed solvent electrolytes and electrolyte solutions at high temperature and high pressure (including near critical electrolyte solutions).

Items 1-5 were consistent with the four goals identified in the original proposal. Items 6-10 represented a broadening of the original goals associated with the addition of Professor John O'Connell as a co-principal investigator beginning 1/1/90. They represent a new focus in the rescarch (electrolyte solutions at high temperature and pressure) as well as a new modeling methodology (fluctuation solution theory) for these and mixed solvent electrolytes.

Progress on this proposed work has been mixed, partly because of personnel linitations and partly because of pursuing interactive opportunitics that may prove quite productive in the near future. 
1. The collaboration with Professor Lado was initiated and a computer program developed, using Professor Lado's programs as a basis, for solving the hypernetted chain approximation for molecules interacting with a Lennard-Jones plus dipole-dipole interaction. This work, performed by postdoctoral worker Sami liaraborni, is the first major step towards developing a program for the study of aqucons solutions using the hypernetted chain approximation. In itself, however, this achievement simply puts is at the level of one or two other research groups and does not lead to publishable results. The next step-cxtension to non-linear molecules-would lead to publishable results. Dr. Karaborni left the research group in August to take up a postdoctoral position in Europe. The work will need to be continued by a graduate student or another postdoctoral worker.

2. Gibbs ensemble simulations are currently underway and are being performed by doctoral candidate Mr. H. Strauch. We have completed a computation of the phase envelope in SPC water (sce Publications in Section 3 below). We have been severely hampernd in our efforts by limited availability of cpu cycles on the DOE Crays. For cxample, for the 1990-1991 fiscal year, a request for 400 hours at LLNL and 200 hours at FSU resulted in an allocation of 70 hours at LLNL and 33 hours at FSU. This has slowed down considerably our ability to produce results. An additional difficulty is that these simulations are the first such simulations to be attempted and are perhajs some of the most complex molecular simulations ever performed, and we have accordingly experienced setbacks, all of which have been magnified by the shortage of cpu cycles. Nevertheless, the first results are expected before years end.

3. The definitive computation of the dielectric constant of SPC water by several different techniques is nearly complete and is currently being written up. Mr. N. Beil's M.S. thesis, defended in August of this year, inrolved the development of a novel method for speeding up Ewald sum molecular dymamics calculations.

4. The development of a mean spherical approximation (MSA) based theory of mixed solvent electrolytes has been proceeding slowly but 
surely: Mr. H. Strauch, the graduate student assigned to this task, has been performing the analysis and it is perhaps $70 \%$ complete. This work is an extension of work by Blum on single solvent electrolytes in the MSA, and one of the main difficultics has been the large number of errors uncovered in Blum's analysis. It is likely that, Mr. Strauch will only have time to complete the analytical work by the time he needs to defend his thesis (the end of this year or early next year) and it will be a task for a future student to implement the analysis numerically.

5. A fourth ycar student, Mr. J. Budd, was assigned the task (as part of his senior thesis) of confirming the experimental measurements of M.S. recipient Ms. R. Osborne on the butanol/water/tetra alkyl ammonium salt systems. He was unable to confirm Ms. Osbornc's observation of salting out behavior over part of the salt concentration range and salting in over the remaining part. The major problem turns out to be in the salt concentration measurement using a specific ion electrode. It appears that this is not a very reliable technique for organic salts, and we were never quite able to calibrate the ion meter sufficiently accurately to determine the salt concentrations with a high degree of precision. Mr. Budd purchased a new still and developed a set of techniques for analyzing concentrations that make extensive use of material balances, and confirmed older results from our lab on alkali halide salts. Before graduation in May, he did not have the opportunity to perform expcriments on the tetra alkyl ammonium salts using the new still so that the results of Osborne remain unconfirmed. We have not attempted until recently to restaff the experimental program because of the opportunity described in item 10 below which would permit one of our students to spend some time at the Danish Technical University performing experiments under the direction of Professor Aa. Fredenslund. We are currently actively recruiting a graduate student to take advantage of this opportunity. We expect that our experimental program will benefit tremendously from the experience prorided by the student spending time in Pro. fessor: Fredenslund's group. 
6 . and 7 . These tasks have been deferred (sec proposed work for the next period) mainly because their optimal formulation turns out to depend more on the final model expressions than was anticipated. This was discovered while examining the osmotic virial equation and MacMillan-Mayer formalisms (see item 8 below). In addition, the mixed solvent work was hindered by Cummings' absence from Virginia on sabbatical leave.

8. The modeling inadequacies have turned out to be at an unsuspected level - thermodynamic rather than molecular. The present models, devcloped over decades of investigation, all assume that there is an ignorable difference among theoretical results from the three normal sets of independent thermodynamic variables: Lewis-Randall (LR) $(T, P, \underline{N})$, Kirkwood-Buff KB) $(T, V, \underline{N})$, and MacMillan-Mayer (MM) $\left(T, V, \underline{N}_{\text {lons }}, \underline{\mu}_{\text {Solvents }}\right)$. Careful evaluation of these differences from experimental density and activity data within the framework of fluctuation solution theory KB derivatives show's that the differences are significant, especially in concentrated solutions. This finding is consistent with the findings of some limited litcrature and particnlarly with recent work using the osmotic virial equation for polymor solutions (especially two-phase aqueous extraction) being done by $\mathrm{H}$. Cabezas at $U$. Arizona and for high temperature calorimetric work described by D. Archer of NIST in Gaithersburg. Fluctuation solution theory gives a particularly straightforward way to compare the different approaches and is the subject of a review paper being written with H. Cabezas. The key to quantitative success secms to be to formulate the molecular model in MM terms and then thermodynamically convert the results to the LR form (the most desirable) using volumetric effects predicted by fluctuation solution theory models KB. This fincling was discussed bricfly in the two invited (and referecd) review papers as well as in prescntations.

9. The formulation of a model using only ionic parameters (all current models use salt parameters, leading to the inconsistency that ions depend on the salt of their origin) is proceeding. The datia base for doing this has been increased considerably during the past year, 
though there has been no graduate assistant to begin new experinental density measurements, as had been anticipated.

10. A number of interactions with other workers in the field were initiated via correspondence and visits supported by other programs. A trip was made by O'Connell to the Oat Ridge National Laboratory where there are excellent people and facilities for experimental examination and correlation of aqueous electrolyte systems at extreme conditions under the direction of $\mathrm{R}$. Mesmer. It is hoped that the collaboration will lead to student visits to make measurements and to access the large amount of data and experience of the workers there. Also, researchers at NIST, principally J. M. H. Levelt Sengers, who are involved in theory and correlation of properties of near-critical aqueous solutions have become interested in using the fluctuation solution theory formalism to test controversies over classical/nonclassical behavior and examine why empirical use of its correlation function integrals yields such simple but powerful descriptions of solute behavior over wide ranges of conditions. In addition, a visit to the Technical University of Iaiserslautern, Germany, stimulated joint interest with Professor G. Maurer in properties of complex ionic systems such as acid gas removal by dissolution. There seems to be a good possibility of exchange programs of students here and there. Another opportunity in Germany that is being explored is with Dr. H. Kricnke of the Wilhelm-Piek University of Rostock (in the former GDR), who has shown independent efforts in the fundamentals of electrolyte statistical mechanics that are connected to our theoretical approach. He may be available for an extended visit in 1991-2 after his one-year appointment in the University of Regensburg, Germany, if funds can be arranged. Finally, initial arrangements were made so that a Virginia student could travel to Denmark to measure vapor-licquid equilibria for mixed solvents containing electrolytes in an apparatus alrcady in use for that purpose in the laboratory of Professor Aa. Fredenslund at the Danish Technical University. The utilization of this opportunity depends on student availability.

Cummings spent two months during the summer at Oak Ridge (as part of lis sabbatical laave) working with H. C. Cochran (from the 
Chemical Tednulogy Division) and J. M. Simonson and R. Mesmer (from the Aqucous Chemistry group) on moleculas simulation of supercritical and near critical aqueous solutions, including investigation of infinitely dilute acpueous electrolyte solutions. This very productive peried resulted in one publication already and two conference presentations in 1991 that will lead to two additionsal publications.

\section{Proposed Research for Period 1/1/91- $12 / 31 / 91$.}

We can express our proposed rescarch for the coming year in terms of the ten items described in the preceding section.

1. We will continue further enhancement of the computer program with the goal of extending it to nonlincar molecules during the coming ycar. This will enable us to use the hypernetted chain approximation to compute the physical properties of pure water. The extcnsion to ionic solutions and mixed solvent clectrolytes will follow.

2. We will continue the Gibbs ensemble simulation work, looking at water/methanol/sodium chloride as the prototypical mixed solvent electrolyte system. We require a much greater allocation of computing resources for this to be possible, however.

3. This is essentially complcte, and no further work is necessary, other than completion of the manuscript.

4. We are actively recruiting from the current intake of graduate students a student who would work on this and molecular simulation for a Pl.D. project. We expect to continue this work during this year and to be in a position to fit to experimental data towards the cned of the year.

j. The experimental work will be pursued through our connections with Fredenslund's group and the Oalk Ridge group. Our main priority remains valiclition of results on the tetrat allyyl ammonium silt systems. 
o. and $\tau$. The expectation is that the modeling work will be sufficiently complete early in the period that the weak electrolyte and multicomponent formulations can be completed. This is principally theoretical work to be carried out by O'Connell, Cummings and other non-student workers. The major objective is to write down for the first time the unicue relations for the cuantities arising naturally in fluctuation solution theory (which can be more easily modeled) with traditional solution properties normally approached by methods of limited generality and accuracy.

8. and 9. The modeling work and its relation to experiment will be able to proceed quickly with student effort since the database and model expressions are available. In addition, measurements of density will be able to be taken in Virginia and/or Oak Ridge. At least two systems with three ions will be measured over wide ranges of composition. The range of ternperature will depend on where the measurements will be made (the range at Virginia is from 275 to $350 \mathrm{~K}$, but higher system temperatures can be studied at Oak Ridge.)

10. The number of collaborations to develop in the period remains to be seen, but the work at NIST should lead to publications both rationalizing some of the empirical results found and suggesting fundamental aspects of near-critical properties.

The work is to be performed by P. T. Cummings. J. P. O'Connell and two half-time graduate research assistants using acistics already available. In addition, an undergraduate student and/or a forcign visitor from $D$ enmark or Germany may also become involved.

\section{Publications and Conference Presenta- tions During Grant Period}

\section{Publications:}

1. de Pablo, J. J., Prausnitz, J. M. Strauch, H. J. and Cummings, P. T., "Molecular Simulation of Water Along the Liquid- Mapor Coexistence 
Curve from $25^{\circ} \mathrm{C}$ to the Critical Point," J. Chem. Physe, accecpted for publication. (1990).

2. Cummings, P. T., Cochran, H. D., Simonson, J. M., Mesmer, R. E. and Laraborni, S., "Structure and Properties of Supercritical Water and Aqueous Solutions," J. Chem. Physe, submittcd for publication. (1990).

3. O'Conncll, J. P., "Thermodynamic Properties of Mixtures from Fluctuation Solution Theory," in Fluctuation Theory of Mixtures, cd. by E. Matteoli and G. A. Mansoori, Taylor and Francis, 1990, p 45.

4. O'Conncll, J. P., "Thermodynamic Properties of Fluids from Fluctuation Solution Theory," Journal of High Pressure-High Temperature, to be published.

5. Cabezas, Jr., H., and O'Connell, J. P., "Some Uses and Misuses of Dilute Solution Thermodynamic Models," IL'EC Rescarch, in preparation.

\section{Conference presentations:}

1. O'Connell, J. P., "Thermodynamic Properties of Fluids from Fluctuation Solution Theory," Invited Lecturc at 12th European Conference on Thermophysical Properties, Vienna, Austria, September, 1990.

2. Cummings, P. T., Cochran, H. D., Simonson, J. M., Mesmer, R. E. and Laraborni, S., "Structure and Properties of Supercritical Water," submitted for presentation at the 11th Symposium on Thermophysical Properties, Junc 23-23, 1991, paper to be subnitted to Int. J. Thermoplyysics.

3. Cummings, P. T., Cochran, H. D., Simonson, J. M., Mesmer, R. E. and Karaborni, S., "Solvation in Supercritical Water," submitted for presentation at the 2nd. Intcrnational Symposium on Supercritical Fluids, May 20-21, 1991, paper to be submitted to J. Supercritical Fluids. 
4. Strauch, H. J. and Cummings, P. T., "Theoretical Appronches to Phase Equilibria in Mixed Solvent Electrolyte Solutions," Chicago, November 11-16, 1990.

5. Cabezas, Jr., H., K. A. Marshaill and J. P. O'Connell, "Fluctuation Solution Theory Model for Aqueous Strong Electrolytes," presented at AICliE Annual Mecting, Chicago, IL, November, 1990. 

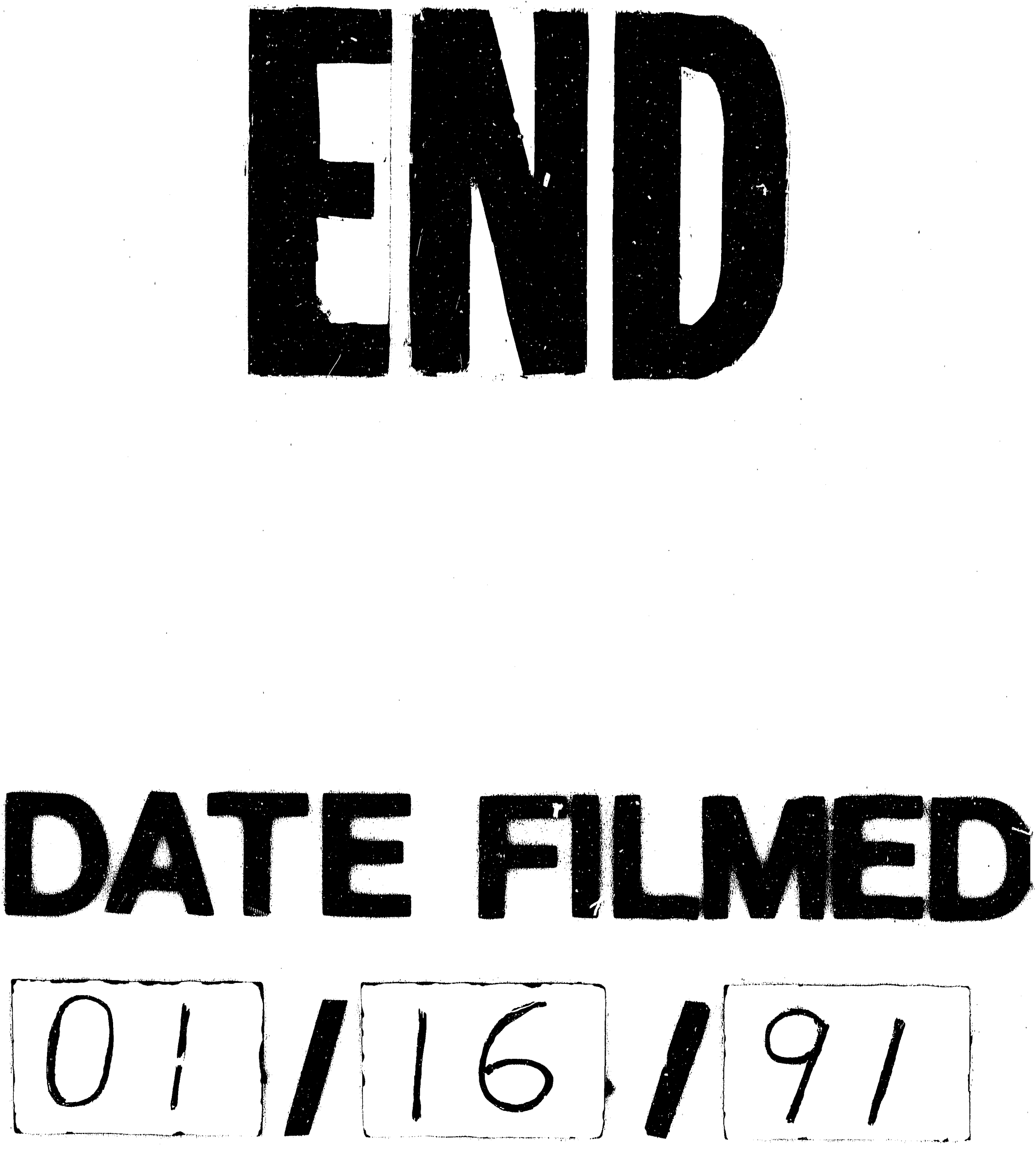